\title{
$\widehat{A}$ Madridge \\ madridge Journal of Nursing \\ Interconnecting Scientific World
}

Research Article

Open Access

\section{Assessment of Blood Group's Awareness among the Omani Population}

\author{
Diyab EM, Al-Wehibi KM, AL-Nasseri JS, AL-Ghadani IS, AL-Baloushi KM, AL-Araimi AH, and Hameed Swadi Hassan \\ School of Pharmacy, College of Pharmacy and Nursing, University of Nizwa, Oman
}

\section{Article Info

*Corresponding author:
Hameed Swadi Hassan
Associate Professor
School of Pharmacy
College of Pharmacy and Nursing
University of Nizwa
Birkat Al-Mouz
Nizwa
Oman
E-mail: hameed@unizwa.edu.om

Received: March 6, 2018

Accepted: April 18, 2018

Published: April 24, 2018

Citation: Diyab EM, Al-Wehibi KM, AL-Nasseri JS, et al. Assessment of Blood Group's Awareness among the Omani Population. Madridge J Nurs. 2018; 3(1): 101-106. doi: $10.18689 / \mathrm{mjn}-1000118$

\begin{abstract}
Copyright: @ 2018 The Author(s). This work is licensed under a Creative Commons Attribution 4.0 International License, which permits unrestricted use, distribution, and reproduction in any medium, provided the original work is properly cited.
\end{abstract}

Published by Madridge Publishers

\begin{abstract}
Blood groups are specific to individuals and are important laboratory investigations in transfusion medicine, tissue transplants and genetic disputes. They exhibit similar serological and physiological characteristics and are inherited according to specific pattern. Thus it was chosen to assess the blood group's awareness among the Omani people during the period of 2012-2016.

The required information was collected from designed questionnaires that include several variables and based on similar previously conducted studies in different parts of the world. All the participants appeared to be healthy and educated. A total of 1800 questionnaires have been distributed in six different regions (willayates) in Oman. Nearly equal number of males and females were participated in the study.

The results show that blood group $O+$ is the dominant blood group (49.1\%), followed by $A+(19.7 \%), B+(17.5)$ and $A B+(4.7 \%)$. In addition, $A B O$ negative groups were only reported in one region and represented a total of $0.7 \%$, although the blood group of $8.3 \%$ of the participant was not determined.

In the present investigation, the majority of the participants seem to be familiar with the blood and its constituents and all of them were found aware of the blood donation, possible diseases transmitted by blood transfusion and the use of the donated blood. In addition, the majority (72\%) were seemed familiar with the hereditary blood disorders. However, the association of the ABO blood groups with serious diseases reported in various studies was difficult to be assessed. All the findings are illustrated in a table and histograms using Microsoft Excel programs and the important, relevant, issues are discussed.
\end{abstract}

Keywords: Blood groups; Rh factor; Diseases associated with blood groups; Oman.

\section{Introduction}

Blood groups are specific to individuals and important determinants in transfusion medicine. They are series of inherited antigens present on the surface of RBCs and different human cells of various tissues and some body secretions [1].

The blood groups as well as the antibodies directed against them were first demonstrated by Karl Landsteiner in 1901 [2]. He found two antigens on the red blood cells; A-antigen and B-antigen. Later, in 1937 in cooperation with Alexander S. Winner the Rh blood group was discovered [3] and since then Rh blood group is regarded as the second most important blood group in blood transfusion.

Before 1939, the only blood group antigens listed were those of the $A B O$ system. Transfusion medicine was entirely based on ABO blood group matching. Despite ABO matching, blood transfusion continued to result in death [4]. 
Relative to transfusion therapy, the Rh blood group becomes the most important after $A B O$ system. This importance is related to the ability of the $D$ antigen to stimulate the production of anti $D$ in $D$-negative individuals. Such production of anti $D$ becomes important to both transfusion therapy and in case of haemolytic disease of newborn [5]. Rh antigens are classified into $\mathrm{Rh}$ positive and $\mathrm{Rh}$ negative antigens. About $15 \%$ of populations are $\mathrm{Rh}$ negative worldwide. Human health requires the avoidance of $\mathrm{Rh}$ - D incompatibility between mother and fetus.

Nowadays, the awareness of blood groups is very essential whether medically, socially or judicially. Medically it is fundamental in case of blood transfusion and tissue transplants. Socially, it helps people to know their blood groups if they want to donate blood at any time of emergency. Judicially, it is a must in case of medico legal issues to assure any parental disputes [6].

Oman is an Arabic country with a total population of 4.748.306 million out of which only 2.443 .200 are Omanis. The remaining 2.053 .314 million is expatriates [7]. The native Omanis are of various ethnic groups some of which have ancestral roots in different countries [8]. It is conceivable that the rare blood groups present in these countries may also be found in Oman as well. Therefore, blood bank services in Oman should keep preparedness to face emergencies related to rare blood groups. WHO has recognized Oman and ranked it $8^{\text {th }}$ best for its health care system [9]. Blood transfusion service has grown to match other disciplines in providing health care to its people [10]. Yet there is a scope for further improvement in area like rare blood donor registry.

Blood groups distribution varies across the world according to population or race. In addition, there are variations within human subpopulations [11]. Among early European races, high frequency of $A$ blood group and very low $B$ blood group were recorded, while among Asiatic races, high frequency of both $A$ and $B$ types were reported. In the Arab world, the overall frequencies of the $O, A, B$, and $A B$ blood groups are $34 \%, 31 \%, 29 \%$ and $6 \%$ respectively.

In southern Saudi Arabia, blood groups distribution was found to represent $56.8 \%$ for blood group $0,33.4 \%$ for $A, 6 \%$ for $B$, and $3.8 \%$ for $A B$. Only $7.2 \%$ of them were found to be negative. It was concluded that these frequencies are similar to those reported in most of the Arab Gulf regions [12, 13].

Among Iraqis (Northern Baghdad), O blood group was the highest (48.03\%), followed by A (23.1\%), B (21.45\%) and $A B(7.4 \%)$. The results indicated that $88.56 \%$ were $\mathrm{Rh}$ positive and $11.44 \%$ were $\mathrm{Rh}$ negative [14]. Approximate findings were recorded in Kurds [15] and Sabians [16].

In healthy Egyptians, blood group $A$ was the most predominant $(36.9 \%)$, followed by $\mathrm{O}(30.7 \%), \mathrm{B}(23.2 \%)$ and $A B(9.2 \%)$. The majorities (92.2\%) of the subjects were $\mathrm{Rh}$ positive and only $7.8 \%$ were Rh negative. Gender had no significant effect on blood group studied [17]. In Khuzestan province (Iran), blood group O was highest in prevalence and $A B$ was the lowest among the ethnicities. In addition, 92.38\% of the donors were Rh positive [18]. Across Nigeria, the results revealed that the $A B O$ group frequencies in the order of $O, A$, $B$, and $A B$ were $52.93 \%, 22.77 \%, 20.64 \%$ and $3.66 \%$. Rh- D positive was $94.90 \%$ [19]. In Bangladesh, the majority (39.8\%) were identified with $\mathrm{B}$ blood group, followed by $\mathrm{O}$ blood group (27.6\%), $A$ (23.5\%) and $A B$ (9.2\%). Rh-D positive individuals were of $97.4 \%$ [20].

In Oman, the distribution of the blood groups and Rh-D factor among pregnant women at Sultan Qaboos University Hospital (2011 - 2013) showed that blood group O represented $52.2 \%$, followed by $A(26.5 \%), B(16.3 \%)$ and $A B(5.1 \%)$. The Rh positive was $92.8 \%$ while the Rh negative was $7.2 \%$ [21].

The relationships of the blood groups and infectious diseases have been pointed out by many researchers. In a study conducted by Anstee, DJ (2010) in tropical Africa, South East Asia and Latin America to observe the distribution of human blood groups and protection against infectious diseases in particular to Helicobacter pylori, norovirus and cholera infections. The results showed that red cells lacking or having altered forms of blood group active molecules are commonly found in regions of the world in which malaria is endemic [22]. In Dore Bafeno area, Southern Ethiopia blood groups $A, B$, and $A B$ shown to be more susceptible to Plasmodium falciparum malarial infection [23].

The ABO blood group has been shown to exert a profound influence on hemostasis and therefore associated with the development of thrombotic cardiovascular adverse events [24]. The results showed that a statistically significant association was found between non $\mathrm{O}$ blood group and the risk of developing subclinical or clinical cardiovascular events. In the US, also, the results showed that blood group A was associated with significant higher serum total cholesterol levels [25]. This analysis of national data confirms previously reported association of blood group A with higher serum total cholesterol levels in white adults and adolescents.

Blood group distribution and association with serious diseases also seen to be interested. Non- group $O$ patients have a greater risk of arterial and venous thromboembolism than patients of group $\mathrm{O}$ and have greater levels of von Willebrand factor (VWF) and factor VIII. On the other hand, one of the first proven associations of a blood group polymorphism with diseases was that between group $O$ and peptic ulceration [22]. The association of ABO blood groups in Iraqis with hypercholesterolemia, hypertension and diabetes mellitus was also studied [26] where the levels of all parameters were found significantly higher in patients with blood group $O$ than other groups, with a decreasing trend from group $A$ to $B$ to $A B$.

In 2014, a meta-analysis of observational studies was conducted to show the association between the blood groups and the risk of cancer [27]. The result showed that blood group A was highly associated with increased risk of gastric cancer, pancreatic cancer, breast cancer, ovarian cancer, and nasopharyngeal cancer. Blood group $\mathrm{O}$ was found to be associated with decreased risk of those types of cancer. Similar lower frequency of blood group $O$ with exocrine pancreatic cancer was found in Milan (Italy) compared to 
other forms of cancer [28] and in the United States during 2010 [29]. For breast cancer, alone, high frequency of blood group $A(53.1 \%)$ was found to be associated followed by $O$ (21.8\%), B (17.5\%) and $A B(5 \%)$ respectively [30].

Blood group incompatibility as a cause of spontaneous abortion was also studied in Canada. The result showed that the incidence of $O$ type mothers who are most likely to have spontaneous abortion was considerably higher [31].

Recently, a successful procedure of transplantation has been introduced [32]. This transplantation is determined by the shared human leukocyte antigens (HLAs) and ABO blood group antigens between donor and recipient. Killer cell receptor and major histocompatibility complex molecules were reported as important determinants of transplant compatibility. Currently, several different genotyping techniques can be used to characterize blood groups. It is now possible to genotype multiple markers and to the extent of a complete sequencing of human genome using next generation sequencer (NGS). This high throughput genotyping platform has been tested for HLA and it is expected that NGS will be used to simultaneously genotype a large number of clinically relevant transplantation genes in near future. In addition, new developments in immune tolerance based therapy; donor recruitment strategies and bioengineering are expected to provide significant advances in the field of transplantation medicine.

\section{Need of the study}

Since the blood group's awareness in Omanis has not been investigated previously and because blood groups are crucial elements in blood and are fundamental in cases of blood transfusions and tissue transplants and play important roles in medico-legal issues, it was chosen to assess such awareness in different regions in Oman. Therefore, the objective of this study is to assess the blood group's awareness among Omanis, the complications related to $\mathrm{Rh}$ incompatibility, possible diseases that might be associated with different blood groups and premarital screening.

\section{Materials and Methods}

The present study is to assess the blood group's awareness among the Omani individuals with the distribution of questionnaires and to motivate the blood donation practice and necessity of premarital screening. Six large heavily populated regions (Wilayates) were chosen as a sample in Oman. These regions include Muscat (the Capital), Nizwa (ALDakhylia), Sur (Al-Sharqiya), Barka, Al-Rustaq and Shohar (AlBatina). The study was conducted during 2012-2016 by using self-administered questionnaires that included demographic parameters and questions about the individual's knowledge of the blood and its constituents, blood groups and Rh factor, personal blood groups, blood donation, diseases transmitted by blood transfusion, possible diseases that might be associated with different blood groups, hereditary blood disorders and premarital screening. The demographic parameters included the individual's age, gender, occupation and education.
A total of 1800 Omani individuals (300 in each region) willing to participate were randomly selected in this study. All participants were well educated and all responded to the questionnaires. The questionnaires were based on similar questionnaires used in previous similar studies [33] and modified to match the required information. These questionnaires were translated in Arabic (the local language) for better interpretation by the selected people and validated. The validity was established by checking in a small population of subjects. All the obtained data were analyzed by using Microsoft Excel programs and illustrated in a table and histograms.

\section{Results}

Based on the results obtained from the questioners, it was found that the largest percentage (61.3\%) was in the age group of 20-40 years and about 39\% were found to be unemployed. All of them were educated and about $47.8 \%$ had academic qualifications. $52.3 \%$ females and $47.7 \%$ males were participated in this study.

According to the statistical data of the investigated sample on the blood and its constituents it was found that the majority of individuals (80\%) were found familiar with the blood as a complex transportation medium and composed of red blood cells, white blood cells and platelets. Also, the vast majority of the participants (95.2\%) were found to be familiar with their own blood groups.

The pattern of the blood group distribution was found to be of $91 \%$ positive and $0.7 \%$ negative, although the blood group of the remaining participants (8.3\%) was unknown. About half $(49.1 \%)$ of the positive individuals were with $\mathrm{O}+$, followed by $A+(19.7 \%), B+(17.5 \%)$ and $A B+(4.7 \%)$ as appeared in fig.1. Negative blood groups were only reported in one of the regions (Sur) and represented $0.3 \%$ for $A-, 0.1 \%$ for $\mathrm{B}-, \mathrm{0.2} \%$ for $\mathrm{O}$ - and lastly $0.1 \%$ for $\mathrm{AB}$ - (table- 1 ).

Table 1. Pattern of blood group distribution

\begin{tabular}{|c|c|c|c|c|c|c|c|c|c|}
\hline $\begin{array}{c}\text { Region } \\
\text { unknown }\end{array}$ & $\mathrm{A}+$ & $\mathrm{B}+$ & $\mathrm{O}+$ & $\mathrm{AB}+$ & $\mathrm{A}-$ & $\mathrm{B}-$ & $\mathrm{O}-$ & $\mathrm{AB}-$ & Unknown \\
\hline Sur & 22.16 & 31.66 & 36.66 & 5.33 & 1.66 & 0.6 & 1.33 & 0.6 & 0 \\
\hline Muscat & 17 & 14 & 57 & 6 & 0 & 0 & 0 & 0 & 6 \\
\hline Sohar & 21 & 19.3 & 55.7 & 4 & 0 & 0 & 0 & 0 & 0 \\
\hline Rustaq & 21 & 16 & 47 & 7 & 0 & 0 & 0 & 0 & 9 \\
\hline Barka & 11 & 8 & 56 & 4 & 0 & 0 & 0 & 0 & 21 \\
\hline Nizwa & 26 & 16 & 42 & 2 & 0 & 0 & 0 & 0 & 14 \\
\hline Average & 19.7 & 17.5 & 49.1 & 4.7 & 0.3 & 0.1 & 0.2 & 0.1 & 8.3 \\
\hline
\end{tabular}

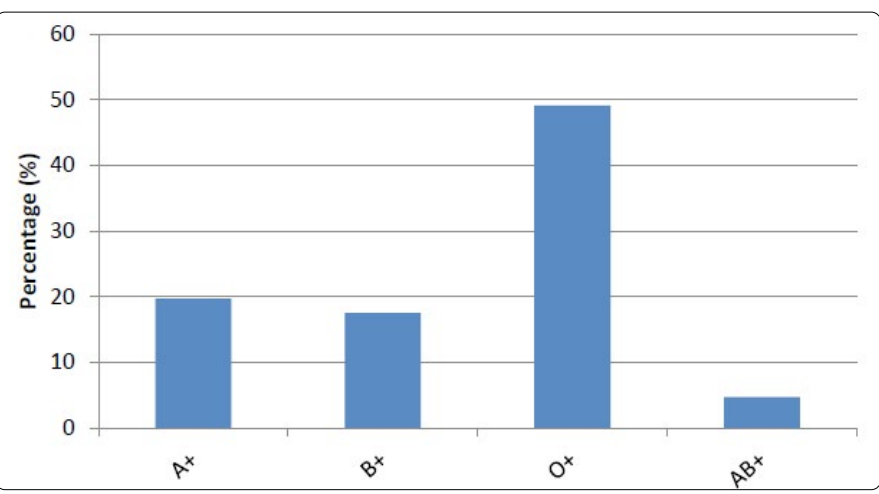

Figure 1. Pattern of blood group distrubution 
The results also showed that about $66.5 \%$ of individuals did not donate blood and the reluctance to donate blood is that it may lead to pain at the site of the insertion of the needle (35\%), dizziness (26\%) and the transmission of blood diseases (39\%) as appeared in fig.2.

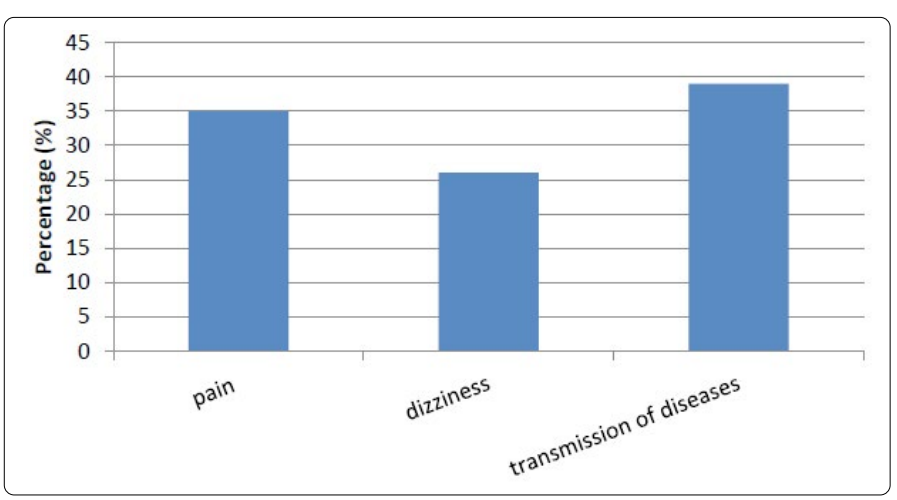

Figure 2. Reason behind reluctance to donate blood

In the present study, the concern of the perception of the investigated individuals about the clinical uses of the donated blood was also intended. It was reported that the donated blood can be used to save life (85\%) in cases of emergency (surgery and accidents) and to treat anaemias (15\%).

Premarital screening also shown to be needed and reported by the majority of the participating individuals (75\%) and the influence of the hereditary blood diseases was also identified by $72 \%$ of cases. Lastly, the possible diseases that might be associated with blood transfusion were reported by $85.8 \%$ of individuals and included AIDS and hepatitis.

\section{Discussion}

Blood types provide a great opportunity for the study of human variation. In fact people rarely take blood types into consideration in selecting mates. There are different literatures that discussed the blood group distribution in various geographical, ethnic and socio-economic groups. In spite of these different results, blood group $\mathrm{O}$ has been reported to be the most common blood group in most of studies, while the blood group $A B$ has been reported as the least common blood group.

All human populations share the same blood systems, although they differ in the frequencies of specific types. The distribution patterns of the blood groups are complex around the world. Some variation may even occur in different areas within one small country [34]. The blood group distribution also shows variety according to races. It was reported that the group $A$ has a wider distribution in Eskimos, the group $B$ in Chinese and Indians, the group $\mathrm{O}$, on the other hand in American and Canadian Indians and Czecoslovakians and those living in Kenya [35].

The need for blood group prevalence is not only important for transfusion medicine but also for organ transplantation and genetic research [36]. In addition, the blood group's awareness in Omani people has not been investigated previously. In this investigation, it was found that the relative percentage of various blood groups does not seem to differ from those which have been recorded. This study has proven that there is dominance of $\mathrm{O}+$ blood group which is similar to what has been reported in most of the Arabian Gulf regions [12]. In our results, $O$ blood group was found to represent $49.1 \%$ followed by $A(19.7 \%), B(17.5 \%)$, and $A B(4.7 \%)$.

Majority of the people also seem to be familiar with the blood constituents and all of them were found aware of the blood donation and the use of the donated blood. Also, the majority $(72 \%)$ were seen familiar with the hereditary blood disorders.

Data from different countries all over the world about the frequency of $A B O$ system, the positive and the negative, as well as, the racial and ethnic distribution is well recorded [37], for comparable findings.

Blood group $\mathrm{O}$ is very common around the world and about $63 \%$ of humans share it. It is found to be high in China [37], Saudi Arabia [12, 37] and Iraq [14-16]. The lowest ratio of O blood group was seen in Czech Republic and Finland [37]. The A blood group was seen to be high in Egypt [17], Finland, Norway and Turkey [37]. The B blood group seen to be high in Bangladesh [20], followed by India and Philippines [37]. The lowest ratio found in Portugal and Netherlands. For AB blood group the highest was seen in Japan and Korea and the lowest value was found in Iceland [37].

The A blood group is somewhat more common around the world than B. About $21 \%$ of all people share it. The highest frequencies of $A$ are found in the Norway followed by Portugal and Japan [37]. The lowest was found among Indians. It seems to be absent among Central and South American Indians [38].

Rh positive blood type is prevalent among the majority of people around the world. $85 \%$ of individuals share the $\mathrm{Rh}$ positive blood type. However, it is more common in some regions than others. Native Americans and Australian Aborigines were very likely $99-100 \% \mathrm{Rh}$ positive before they began interbreeding with people from other parts of the world. Most Sub-Saharan African populations are around 9799\% Rh positive. East Asians are 93-99\% Rh positive. Europeans have the lowest frequency of this blood type; they are $83-85 \%$ Rh positive. The lowest known frequency is found among the Basques of the Pyrenees Mountains between France and Spain. They are only $65 \%$ Rh positive [39].

In Nigeria, the pattern of $A B O$ group among students of Hassan Usman Katisma polytechnic was also identified [40]. The results showed that sex or age has no relationship with blood groups. The Rh positive is demonstrated and accounted for $97 \%$. People having the Rh negative were very few and represented only by $1.8 \%$ for $B$ blood group and $0.88 \%$ for $O$ blood group. Blood groups $A$ Rh negative and $A B$ Rh negative were not encountered however [40]. The low percentage of $\mathrm{Rh}$ negative (5.1\%) was also reported across Nigeria [19]. In the sample investigated in this study $\mathrm{Rh}$ negative only reported in one region (Sur) and represented $0.7 \%$, although the blood group of $8.3 \%$ of participants were not recorded (unknown).

Identification of the prevalence of Rh-D negative in women is very important to minimize the complications of 
Rh-D alloimmunization in pregnancy [21]. The prevalence of Rh-D negative blood type among pregnant women in Oman was found to represent $7.3 \%$. In Saudi Arabia the prevalence was $7.5 \%$ and the same was reported in South India [41, 42]. It is noted that the prevalence of Rh-D negative in the Omani population falls closer to the prevalence of $5-8 \%$ of African Americans [21]. This is important historically as Oman had cultural and trade relations with East Africa and as such the current population in Oman is admixture between Caucasian, African and Asian ancestries [43].

In addition to the current practice of serologic testing of blood groups, the progress in molecular diagnosis allows the prediction of phenotype based on the knowledge of the molecular basis of the currently used antigens. This will improve the process of blood matching for the transfusion $[39,44]$.

Finally, the association of the $A B O$ blood groups with the serious diseases that have been reported in various literatures [22-30], was difficult to be assessed in this study. However, the present study may also help to promote the awareness of the whole community rather than the selected individuals about such association since the reported association was based on clinical evidences.

\section{Conclusion}

Based on the obtained results, the pattern of the blood group distribution in Oman was found to be similar to those reported in most areas of Arabian Gulf Regions, Iraq, and the neighboring Khuzestan (Iran) province and in some countries all over the world. Some variation may even occur in different areas within one small country. The blood group distribution also shows variety according to races. Rh negative was detected in only one region and represented very small percentage. Again Rh blood negative is very rare across the world and represents only $15 \%$ of the $A B O$ blood system. The knowledge of the $A B O$ system is also important in transfusion medicine and tissue transplants and play important role in medico legal issues. So many diseases are reported to be associated with of the different types of the ABO system. This might also help to increase the awareness of the people, not only in Oman, but in different parts of the world about the possibility of such associations.

\section{Recommendations}

Since $8.3 \%$ of the cases investigated in this study were found to be unfamiliar with their own blood groups and because blood groups are crucial elements in blood transfusion, tissue transplants and parenteral disputes, it is recommended that all people in the community should be made to become socially aware of their own blood groups and their clinical significance. This might be achieved by social health media in the community and health programs in school curricula. Our future study will focus on other regions (Willayates) in Oman which have not been investigated in this study to give more comprehensive results.

\section{Acknowledgment}

We would like to express our thanks and gratitude to the University of Nizwa and the College of Pharmacy and Nursing, School of Pharmacy for offering this opportunity to conduct this research via the provision of the academic programs. Our thanks are also extended to the respected participants without their kind participation this study cannot be conducted.

\section{References}

1. Hartmann G. Group antigens in human organs. Army Medical Research Lab Fort Knox Ky; 1970.

2. Daniels G. Human blood groups. John Wiley \& Sons. 2008.

3. Watkins WM. The $A B O$ blood group system: historical background. Transfusion medicine. 2001; 11(4): 243-65. doi: 10.1046/j.1365-3148.2001.00321.x

4. Harmening DM. Modern blood banking and transfusion practices. FA Davis; 2012.

5. Rudmann SV. Textbook of blood banking and transfusion medicine. Elsevier Health Sciences; 2005

6. Sembulingam K, Sembulingam P. Essentials of Medical Physiology. Jaypee Brothers Medical Publishers (P) Ltd. New Delhi, India. 2006

7. Oman Information Services. 2018.

8. Joshi S, Pathare A, Al-Marhoubi A, Al-Muhaidry R, Ashraf T, et al. A profile of rare bloods in Oman. Asian journal of transfusion science. 2013; 7(2): 162. doi: 10.4103/0973-6247.115598

9. World Health Organization; 2000.

10. Joshi SR, Al-Bulushi SN, Ashraf T. Development of blood transfusion service in Sultanate of Oman. Asian journal of transfusion science. 2010; 4(1): 34-40. doi: 10.4103/0973-6247.59390

11. ABO blood groups. Centre for Arab Genomic Studies; A Division of Sheikh Hamdan Award for Medical Science.

12. Sarhan MA, Saleh KA, Bin-Dayem SM. Distribution of ABO blood groups and rhesus factor in Southwest Saudi Arabia. Saudi Med J. 2009; 30(1): 116-119.

13. Al-Arrayed S, Shome DK, Hafadh N, Amin S, AL Mukhareq H, Al Mulla M, et al. $A B O$ blood group and Rhd phenotypes in Bahrain: results of screening school children and blood donors. Bahrain Med Bull. 2001; 23(3): 112-115.

14. Saad M Saleh, Abood AS. ABO and Rh (D) Blood Groups' Distribution and Gene Frequencies in North Baghdad population-Iraq. International Journal of Scientific and Engineering Research. 7(8): 581-584.

15. Jaff MS. $A B O$ and rhesus blood group distribution in Kurds. J Blood Med. 2010; 1: 143-146. doi: 10.2147/JBM.S12262

16. ALubaidi $A E$, Almohaidi AM, Alkhamesi MB, Ali NJ. Gene frequencies of $A B O$ and rhesus blood groups in Sabians (Mandaeans), Iraq. Baghdad Science Journal. 2014; 11(2).

17. Homouda FA. Distribution of $A B O$ and Rh-D blood groups in healthy Egyptian population. CU Theses. 2012.

18. Paridar M, Mahmodian Shoushtari M, Kinani B, Nori B, Shahjahani M, Khosravi $A$, et al. Distribution of $A B O$ blood groups and rhesus factor in a large Scale Study of different cities and ethnicities in Khuzestan province, Iran. Egyptian Journal of Medical Human Genetics. 2016; 17(1): 105-109. doi: 10.1016/j.ejmhg.2015.07.004

19. Anifowoshe AT, Owolodun OA, Akinseye KM, lyiola OA, Oyeyemi BF, et al Gene frequencies of $\mathrm{ABO}$ and $\mathrm{Rh}$ blood groups in Nigeria. Egyptian Journal of Medical human genetics. 2017; 18(3): 205-210. doi: 10.1016/j. ejmhg.2016.10.004

20. Sultana R, Rahman Z, Helali AM, Yousuf R, Mustafa S, Salam A, et al. Study of $A B O$ and $\mathrm{RH}-\mathrm{D}$ Blood Groups among the common people of capital city of Bangladesh. International Journal of Pharmacy and Pharmaceutical Sciences. 2013; 5(3): 814-6. 
21. Al-Dughaishi T, Al Harrasi $\mathrm{Y}, \mathrm{Al}$-Duhli $\mathrm{M}, \mathrm{Al}$-Rubkhi I, Al-Riyami $\mathrm{N}, \mathrm{Al}-$ Riyami $A Z$, Pathare AV, Gowri $V$ et al. Red cell alloimmunization to rhesus antigen among pregnant women attending a tertiary care hospital in Oman. Oman medical journal. 2016; 31(1): 77. doi: 10.5001/omj.2016.15

22. Anstee DJ. The relationship between blood groups and disease. Blood. 2010; 115(23): 4635-43. doi: 10.1182/blood-2010-01-261859

23. Zerihun $T$, Degarege $A$, Erko B. Association of $A B O$ blood group and Plasmodium falciparum malaria in Dore Bafeno Area, Southern Ethiopia. Asian Pacific journal of tropical biomedicine. 2011; 1(4): 289-94. doi: 10.1016/S2221-1691(11)60045-2

24. Capuzzo E, Bonfanti C, Frattini F, Montorsi P, Turdo R, Previdi MG, et al. The relationship between $A B O$ blood group and cardiovascular disease: results from the Cardiorisk program. Annals of translational medicine. 2016; 4(10): 189. doi: 10.21037/atm.2016.03.58

25. Gillum RF. Blood groups, serum cholesterol, serum uric acid, blood pressure, and obesity in adolescents. Journal of the National Medical Association. 1991; 83(8): 682-688.

26. Jassim WE. Association of $A B O$ blood group in Iraqis with hypercholesterolemia, hypertension and diabetes mellitus. East Mediterr Health J. 2012; 18(8): 888-91.

27. Zhang $B L$, He N, Huang $Y B$, Song FJ, Chen $K X$ et al. ABO blood groups and risk of cancer: a systematic review and meta-analysis. Asian Pac J Cancer Prev. 2014; 15(11): 4643-50.

28. Iodice $S$, Maisonneuve $P$, Botteri $E$, Sandri MT, Lowenfels $A B$. ABO blood group and cancer. European journal of cancer. 2010; 46(18): 3345-50. doi: 10.1016/j.ejca.2010.08.009

29. Greer JB, Yazer MH, Raval JS, Barmada MM, Brand RE, Whitcomb DC, et al. Significant association between $A B O$ blood group and pancreatic cancer. World journal of gastroenterology. 2010; 16(44): 5588-91.

30. Aly R, Yousef A, Elbably $O$. Association of $A B O$ blood group and risk of breast cancer. J Blood Disorders Transf. 2014; 5: 241

31. Takano K, Miller JR. ABO incompatibility as a cause of spontaneous abortion: evidence from abortuses. Journal of medical genetics. 1972; 9(2): $144-150$
32. Edinur HA, Siti M Manaf, Nor F che Mat. Genetic barriers in transplantation medicine. World Journal of Transplantation. 2016; 6(3): 532-541. doi: 10.5500/wjt.v6.i3.532

33. Alfouzan N. Knowledge, attitudes, and motivations towards blood donation among King Abdulaziz Medical City Population. International journal of family medicine. 2014. doi: 10.1155/2014/539670

34. Kolmakova GN, Kononova LL. The prevalence of $A B O$ blood groups among persons of native nationality in Buryatia. Sudebno-meditsinskaia ekspertiza. 1999; 42(2):15-6.

35. Included in Transplants/Organ Donation. Blood/ Hematology. 2011.

36. Pasha AK, Hashir MM, Khawar S. Frequency of $A B O$ blood groups among medical students. Journal of Surgery Pakistan (International). 2009; 14(2): 93-95.

37. http://eu.Wikipedia.Org/wiki/blood type

38. http://anthro. palomar.edu./vary/vary_3.htm

39. Avent ND. Large-scale blood group genotyping-clinical implications. British journal of haematology. 2009; 144(1): 3-13. doi: $10.1111 / \mathrm{j} .1365-2141.2008 .07285 . x$

40. Sani Mannir. ABO group among students of Hassan Usman Katisna Polyclinic. International Journal of Research Studies in Biosciences. 2014; 2(10)

41. Bondagji NS. Rhesus alloimmunization in pregnancy. A tertiary care center experience in the western region of Saudi Arabia. Saudi Med J. 2011; 32(10): 1039-1045

42. Varghese J, Chacko MP, Rajaiah M, Daniel D. Red cell Alloimmunization among antenatal women attending a tertiary care hospital in south India. Indian Med Res. 2013; 138: 68-71.

43. Pathare AV, Al Zadjali S, Misquith R, Alkindi SS, Panjwani V, Lapoumeroulie C, et al. Warfarine Pharmacogenetics: polymorphisms of the CYP2C9, CYP4F2, and VKORCI loci in a genetically admixed Omani population. Human Biol. 2012; 84(1): 67-77. doi: 10.3378/027.084.0103

44. Anstee DJ. Red cell genotyping and the future of pretransfusion testing Blood. 2009; 114(2):248-56. doi: 10.1182/blood-2008-11-146860 